\title{
Exogenous Plant Growth Regulators Show Promise for Management of Alternate Bearing in Pecan
}

\author{
Marisa Y. Thompson ${ }^{1}$ \\ Department of Plant \& Environmental Sciences, New Mexico State \\ University, Las Cruces, NM 88003
}

\section{Jennifer Randall}

Department of Entomology, Plant Pathology, and Weed Science, New Mexico State University, Las Cruces, NM 88003

\section{Richard J. Heerema}

Department of Plant \& Environmental Sciences, New Mexico State University, Las Cruces, NM 88003

\section{Dawn VanLeeuwen \\ Department of Economics, Applied Statistics, and International Business, New Mexico State University, Las Cruces, NM 88003}

Additional index words. Carya illinoinensis, pecan flowering, phytohormones, bioregulators, ethephon, ReTain, ProGibb

\begin{abstract}
Successful commercial pecan [Carya illinoinensis (Wangenh.) K. Koch] production relies on mitigation of alternate bearing, which is a function of pistillate flower production. Mechanisms of floral initiation in pecan are not well understood. Our objective was to assess the impact of select plant growth regulators (PGRs) on return bloom for commercial application in pecan trees grown in the Southwestern United States. A 2-year study evaluated effects of ethephon, aminoethoxyvinylglycine (AVG), and gibberellin $\mathrm{GA}_{3}\left(\mathrm{GA}_{3}\right)$ on subsequent season return bloom in fruiting and nonfruiting pecan shoots. Cultivars used were mature Western and immature Western and Pawnee. Effects of PGRs on return bloom of nonfruiting shoots were different from fruiting shoots. As compared with untreated control, a $\mathbf{G A}_{3}$ treatment on fruiting shoots of mature 'Western' trees increased the number of flowers per new shoot by $125 \%$. For nonfruiting shoots on the mature 'Western' trees, the number of flowers per new shoot decreased significantly by all PGR treatments and as much as $93 \%$ for AVG. In previously nonfruiting shoots on the immature 'Western' trees, a GA $_{3}$ treatment reduced the number of flowers per new shoot in the next season by $88.2 \%$. Results from immature 'Pawnee' shoots did not show statistically significant differences. The effects of these PGRs on subsequent season flowering in pecan are complex. This study suggests that PGRs can be used to increase or decrease cropload through effects on return bloom and therefore have potential uses for mitigating alternate bearing.
\end{abstract}

Alternate bearing (AB) poses a major challenge for the pecan [Carya illinoinensis (Wangenh.) K. Koch.] industry (Wood, 2003). $\mathrm{AB}$ refers to a tendency for wide season-to-

Received for publication 2 Jan. 2019. Accepted for publication 29 Mar. 2019.

Based on part of a dissertation in partial fulfillment of the requirements for a $\mathrm{PhD}$ degree at New Mexico State University (NMSU). Thanks to Christian Barraza, Greg Daviet, Jacob Lilley, Dave Lowry, Esteban Morales, Sara Moran, Cody Runyan, Frank Sholedice, and the crew at the NMSU Leyendecker Research Center for their help in the field and with the manuscript. The authors acknowledge the assistance of the technical staff of the collaborators and partial funding for this project provided by the U.S. Department of Agriculture Specialty Crop Initiative, New Mexico Specialty Crop Block Grants, administered by the New Mexico Department of Agriculture (12-25-B-1686), as well as the NMSU Agricultural Experiment Station. ${ }^{1}$ Corresponding author. E-mail: risi@nmsu.edu. season fluctuations in cropping intensity. This is often expressed as a heavy (on) cropload season followed by a light (off) cropload season (i.e., a biennial bearing pattern). Whether the season is an on or off year, productivity and yield are directly dependent on the success or failure of the flowering process (Sedgley, 1990).

Flowering control is complex and involves several environmental (e.g., light and temperature) and endogenous cues (e.g., carbohydrates and phytohormones). Wood (1983) showed for pecan that levels of the endogenous phytohormone gibberellic acid (GA) examined in bud tissues peak dramatically in the days immediately surrounding budbreak. Exogenously applied PGRs, such as GA and ethylene, among others, have been studied for the intention of mitigating $\mathrm{AB}$ intensity in several fruit tree species, including apple (Malus $\times$ domestica Borkh.), citrus (Citrus spp.), mango (Mangifera spp.), wal- nut (Juglans spp.), and pecan (Greene, 2000; Hagemann et al., 2015; Hassankhah et al., 2018; Muñoz-Fambuena et al., 2012; Wood, 2011a, 2011b; Wood et al., 2009). Application of ethephon-suppressed endogenous gibberellin $\mathrm{GA}_{3}\left(\mathrm{GA}_{3}\right)$ production in apple when applied in early spring increased subsequent season flowering and fruit set (Ebert and Bangerth, 1981). Timing is key for PGR treatment, and GA application at full bloom was the most effective timing for reducing return bloom in apple (Tromp, 1982). In a study of $\mathrm{GA}_{4+7}$ exogenous applications on apple trees of varying cropload, researchers found the reduction in subsequent season return bloom to be dependent on the intensity of the cropload, and the effect was most pronounced on trees with a moderate cropload vs. either a heavy or light cropload (Schmidt et al., 2009).

Ethephon, a synthetic ethylene-generating compound, was found to control flowering in an $\mathrm{AB}$ apple orchard both by increasing flowering in off years by $33 \%$ when applied the previous year and by decreasing flowering in on years by $17 \%$ when applied in the previous year in the weeks after full bloom (WAFB) (Bukovac et al., 2006). Wood (2011b) studied effects of various GAs, prohexadione-ca (a GA biosynthesis inhibitor), ethephon, and other PGRs on immature and mature pecan trees, both at the level of whole trees and individual shoots, when applied 3, 6, and 9 WAFB. After GA treatment, the percentage of subsequent season fruiting shoots decreased in comparison with the control group, as did the number of nuts per cluster. These results were consistent whether the whole tree was treated or just individual shoots, and he concluded that GA treatments may be useful for the mitigation of $\mathrm{AB}$ in pecan.

Exogenous application of ethephon to whole immature trees in Wood's (2011b) study increased both the subsequent season's percentage of new shoots with flowers and the number of nuts per cluster compared with the control group. The ethylene inhibitor AVG was proposed as a mitigation tool for $\mathrm{AB}$ because it increases fruit retention in off years and has a carryover effect in which subsequent season on-year production was reduced (Wood, 2011a, 2011b; Wood et al., 2009).

Our objective was to better understand the effects of exogenous PGR applications on return bloom in mature and immature protandrous pecan cultivars grown in New Mexico. We studied three different PGRs (ethephon, two concentrations of $\mathrm{GA}_{3}$, and $\mathrm{AVG}$ ) applied to individual shoots that were either fruiting or nonfruiting in trees of different maturity and cultivars.

\section{Materials and Methods}

Characteristics of experimental orchards. The three study orchards were located in the Mesilla Valley, NM, United States (lat. $32^{\circ} 19^{\prime} 35 \mathrm{~N}$, long. $106^{\circ} 46^{\prime} 31^{\prime \prime} \mathrm{W}$; elevation $1201 \mathrm{~m}$ ). This region has an average annual precipitation of $222 \mathrm{~mm}$ (Malm, 2003). 
Environmental data collected at a nearby weather station on the New Mexico State University (NMSU) main campus reported $210 \mathrm{~mm}, 320 \mathrm{~mm}$, and $215 \mathrm{~mm}$ of rainfall in 2014, 2015, and 2016, respectively (New Mexico Climate Center, 2016).

The mature 'Western' (synonym 'Western Schley') experimental trees were planted in 1965-72 and had 'Ideal' (synonym 'Bradtrees were selected from the NMSU Linwood Nursery Research Orchards at the Leyendecker Plant Science Research Center near Mesquite, NM. Immature 'Western' trees were in their fourth leaf and fifth leaf and the immature 'Pawnee' trees were in their fifth leaf and sixth leaf in 2015 and 2016, respectively. The immature 'Pawnees' were grafted to open-pollinated 'VC1 68' seedling rootstocks, the immature 'Westerns' to seedling 'Shoshone' rootstocks, and the mature 'Westerns' to unknown rootstocks. Soils in the mature orchard are primarily Harkey loam (coarse silty, mixed, superactive, calcareous, thermic Typic Torrifluvents), and soils in the immature orchards are primarily Armijo clay loam (fine, smectitic, thermic Chromic Haplotorrerts) and Glendale clay loam (fine silty, mixed, superactive, calcareous, thermic Typic Torrifluvents) (Soil Survey Staff, 2017). Soils in this area of New Mexico are characterized as having $\mathrm{pH}>7.5$ (Chang, 1952).

Orchards were flood irrigated with water from the Rio Grande and pumped well water. Irrigation scheduling, insecticide application, fertilization, and weed control were carried out by the orchard managers and were consistent with recommended commercial production practices. The 12.5-ha area surrounding the six mature 'Western' experimental trees demonstrated slight $\mathrm{AB}$ tendency with yields of $2480,3160,2520$, and 3230 $\mathrm{kg} \cdot \mathrm{ha}^{-1}$ in 2013, 2014, 2015, and 2016, respectively.

Experimental design. Six trees were selected from the mature Western cultivar pecan orchard. Structured as a generalization of a randomized block experiment, each tree was a single block with shoots representing experimental units. Treatments were applied to both fruiting and nonfruiting (vegetative) shoot populations, and therefore the factor "fruiting status" had two levels. Because each treatment was applied to three randomly chosen shoots within each tree and fruiting status, in 2014 there were three treatments, and so a total of 18 shoots (9 fruiting and 9 nonfruiting) per tree were used. In 2015, there were five treatment levels, so a total of 30 shoots (15 fruiting and 15 nonfruiting)

Four 'Western' and four 'Pawnee' trees also were selected from the immature orchards, again with each tree as a single block. Only nonfruiting shoots were chosen in 2014 in the immature 'Pawnee' and 'Western' trees. In 2015, there was sufficient fruiting in the 'Pawnee' trees to include both fruiting and nonfruiting shoots, but not in the immature 'Western' trees. ley') pollinizers planted nearby. Immature were identified for use in the study.
In 2014, treatments were 1) nontreated control (consisting of distilled water plus surfactant, Kinetic), 2) $\mathrm{GA}_{3}$ (ProGibb 4\% at $50 \mathrm{mg}$ a.i./L; Valent BioSciences Corporation, Libertyville, IL) plus surfactant, and 3) ethephon [(2-chloroethyl) phosphonic acid, Ethrel at $100 \mathrm{mg}$ a.i./L; Bayer CropScience, Inc., Calgary, Alberta, Canada] plus surfactant. In 2015, two additional PGR treatments were a double rate $(2 x)$ of $\mathrm{GA}_{3}$ (ProGibb 4\% at $100 \mathrm{mg}$ a.i./L) plus surfactant and the ethylene inhibitor AVG (ReTain at 0.88 g. $\mathrm{L}^{-1}$; Valent BioSciences Corp., Libertyville, IL) plus surfactant. In each tree and in each year, sun-exposed lateral shoots were tagged and randomly assigned to a treatment. For fruiting shoots, only those with exactly three nuts were chosen. In the mature trees, all nonfruiting shoots possessed between five and seven leaves per shoot.

Treatments were applied using handheld bottle sprayers and plastic funnel-shaped collars to reduce the possibility of chemical drift during application. For both years, PGR applications were scheduled at $\approx 3,6$, and 9 WAFB in the mature orchard and at parallel dates in the immature orchards, depending on irrigation and orchard management schedules and weather (Table 1).

Data collection and statistical analysis. Return bloom response variables were analyzed by year using generalized linear mixed models (GLMMs) with fixed effects for treatment, fruiting status and their interaction, and a random tree effect. Flower count per new season shoot, total number of new shoots from treated shoots, flowers per cluster, and percentage of new shoots with flowers were analyzed using the normal response distribution and using the identity link, and total number of flowers per previous season shoot was analyzed using a negative binomial response distribution and using the $\log$ link.

Missing data occurred in both years, mainly from branch damage before return bloom data were collected and dead shoots. Two significant hail events, 21 Oct. 2015 and 18 May 2016, were reported by citizens within $2 \mathrm{~km}$ of the mature commercial experimental orchard before collection of return bloom data in 2016 (Community Collaborative Rain, Hail \& Snow Network, 2018). No such events were reported during the experimental period before 2015 return bloom data collection. The level of shoot loss in year 2 was unanticipated, with substantial data loss in the mature orchard due to overwinter branch damage (56 of 180 shoots) and shoot death (34 shoots). The authors recommend inclusion of more within-tree replication in future studies for two reasons:

Table 1. Dates of plant growth regulator applications in mature and immature pecan orchards, 2014-2015.

\begin{tabular}{lcrr}
\hline \multicolumn{2}{c}{ Mature 'Western' } & \multicolumn{2}{c}{ Immature 'Pawnee' and 'Western' } \\
\cline { 2 - 3 } \cline { 4 - 4 } 2014 & 2015 & 2014 & 2015 \\
\hline 6 June & 4 June & 17 June & 12 June \\
27 June & 24 June & 8 July & 3uly \\
18 July & 16 July & 29 July & 4 Aug. \\
\hline
\end{tabular}

potentially significant overwinter losses in one or more years, and to allow for preplanned assessment of treatment effects on shoot death

Least significant difference was used for post hoc pairwise comparisons applied to the highest-order significant effect. For all analyses, the outlier strategy was used, with outliers defined as data points producing marginal or conditional studentized residuals with magnitudes greater than three (Ramsey and Schafer, 2002). For analyses using nonidentity links, inverse linked (data scale) or odds ratio estimates were reported. Significance was defined as $P \leq 0.05$ for all analyses. GLMM analyses were run using SAS PROC MIXED and PROC GLIMMIX version 9.4 software (SAS Institute Inc., Cary, NC).

\section{Results and Discussion}

Return bloom. In year 1 , no significant main effects or interactions were found in any of the flowering parameters in mature and immature trees (data not shown). This firstyear result prompted the addition of two treatments, $\mathrm{GA}_{3}(2 \mathrm{x})$ and $\mathrm{AVG}$, in the second experimental year.

In year 2, the number of flowers per new shoot was $125.3 \%$ higher after treatment with $\mathrm{GA}_{3}(2 \mathrm{x})$ than control shoots in the previously fruiting mature 'Western' shoots. The number of flowers per cluster in these same previously fruiting shoots was marginally higher for shoots treated with $\mathrm{GA}_{3}(2 \mathrm{x})$ compared with the control fruiting shoots (Table 2).

The results of PGR application on previously nonfruiting shoots were more extreme. Compared with the nonfruiting control shoots, all treated nonfruiting shoots in the mature 'Western' trees displayed a reduction in total number of flowers per new shoot, ranging from $52.1 \%$ to $93.3 \%$. This effect was also evident as a nonsignificant trend of a lower percentage of new shoots with flowers in the mature 'Western' nonfruiting shoots. In year 2, both the treatment main effect and the interaction of treatment by fruiting status were significant; the untreated control and AVG data were the most striking (Table 2). It appears that AVG may have switched the $\mathrm{AB}$ tendency in comparison with the control. In previous work, $\mathrm{GA}_{3}$ and $\mathrm{GA}_{4+7}$ decreased both the percentage of new shoots with flowers and the number of flowers per cluster compared with the untreated control when applied to nonflowering shoots of 25-year-old 'Pawnee' trees (Wood, 2011b). Wood (2011b) concluded that GAs inhibited floral induction for the subsequent 
season. Our results, and those of Wood (2011b), are consistent with the conclusion that fruiting status determines production in the subsequent season and support the notion that phytohormones play an important role in AB.

Crucial to the interpretation of these findings is the understanding that phytohormones and PGRs do not have single functions in plants. A complex balance of interrelations between PGRs exists such that application of one PGR may be inhibited or stimulated by the presence of another phytohormone or PGR (Jaillais and Chory, 2010; Moyers, 2018). Endogenous phytohormone levels were not monitored in this study, but it is likely that they had a role in determining return bloom intensity. It is also possible that the timing or rates of PGR applications affected the degree or direction of our results.
Additional research is needed on the effects of exogenous PGRs in New Mexico pecans at both the shoot and whole-tree levels before a formal recommendation on PGR usage can be specified.

New shoots. For the return bloom parameter number of "new shoots," responses were also different for shoots that were fruiting vs. nonfruiting at the time of PGR application. Overall, previously fruiting shoots bore more new shoots than previously nonfruiting shoots in both years; that is, the fruiting main effect was significant (Tables 2 and 3 ). In previously fruiting shoots, both of the $\mathrm{GA}_{3}$ application rates in the mature 'Western' trees marginally decreased $(P=0.0522)$ the number of new shoots in year 2 (Table 2 ). Although not statistically significant, a data trend emerged showing increased numbers of new shoots with ethephon application in both years in the mature 'Western' and in the second year for the immature 'Pawnee' trees, but only when shoots were previously fruiting (Tables 2 and 3). Results from nonfruiting shoots in the immature 'Western' trees tended to be similar to those in the mature 'Western' trees (Tables 2 and 4).

The fruiting status main effect on the number of new shoots is remarkable. Fruiting shoots yielded a statistically higher total number of new shoots in both the mature 'Western' and the immature 'Pawnee' orchards (Tables 2 and 3). In the 2016 immature 'Pawnee' trees, the estimated number of new shoots was $3.06 \pm 0.1928$ for fruiting shoots vs. $2.24 \pm 0.2162$ from previously nonfruiting shoots. Fruiting shoots in year of shoot selection and PGR application were more robust than nonfruiting shoots, and this may have affected the number of new shoots

Table 2. Effects of exogenous application of plant growth regulators [untreated control, ethephon, gibberellic acid $\left(\mathrm{GA}_{3}\right)(1 \mathrm{x}$ and $2 \mathrm{x})$, and aminoethoxyvinylglycine (AVG)] on mature 'Western' pecan fruiting and nonfruiting shoots in 2016. Least squares means (lsmeans) are reported of each subsequent season return bloom parameter. Lower case a or b within row (treatment) indicates that lsmeans of fruiting and nonfruiting shoots within that return bloom parameter sharing the same letter do not differ significantly $(P \leq 0.05)$. Upper case A or B within column (return bloom and fruiting status) indicates that estimates sharing the same letter do not differ significantly $(P \leq 0.05)$.

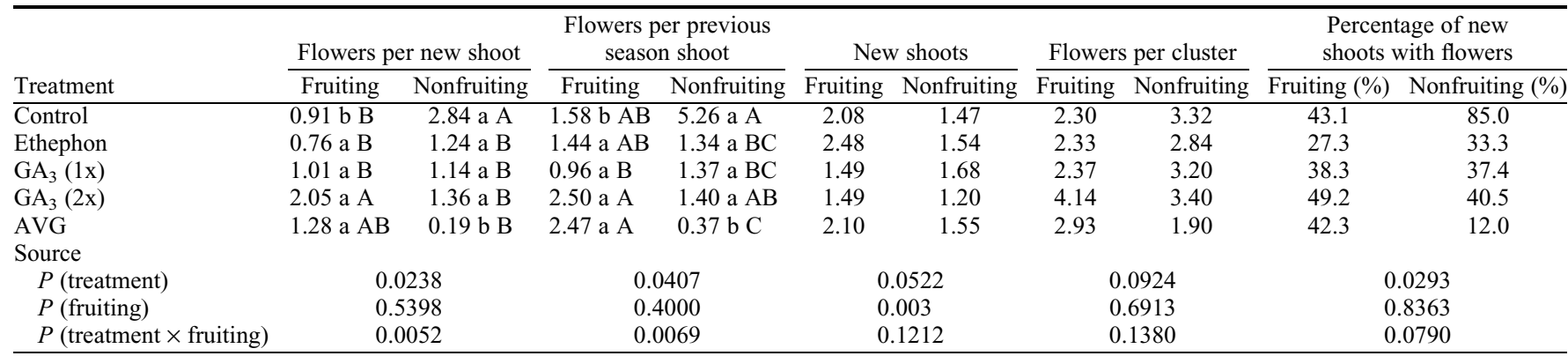

Table 3. Effects of exogenous application of plant growth regulators [untreated control, ethephon, gibberellic acid $\left(\mathrm{GA} \mathrm{A}_{3}\right)$ (1x and $\left.2 \mathrm{x}\right)$, and aminoethoxyvinylglycine (AVG)] on immature 'Pawnee' pecan fruiting and nonfruiting shoots in 2016. Least squares means (lsmeans) are reported of each subsequent season return bloom parameter.

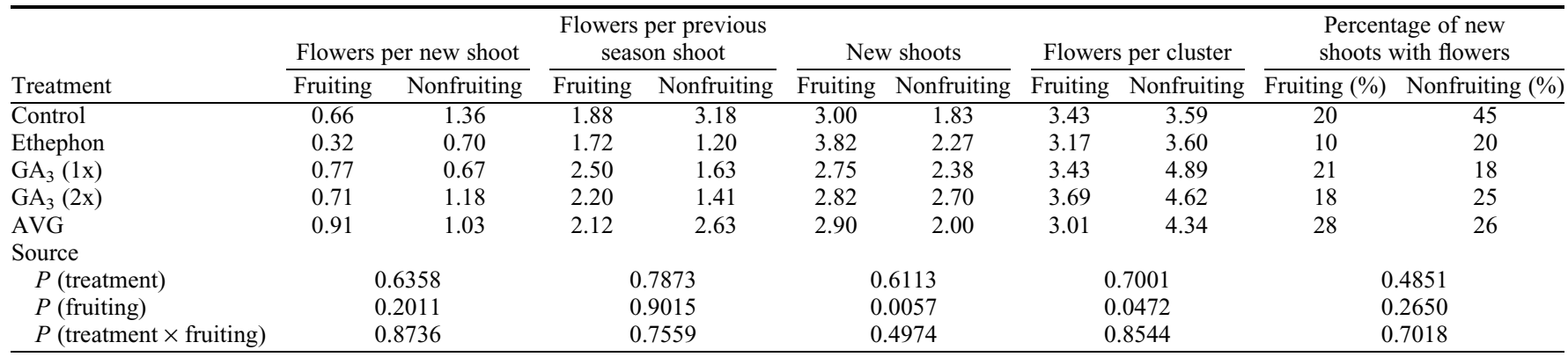

Table 4. Effects of exogenous application of plant growth regulators [untreated control, ethephon, gibberellic acid $\left(\mathrm{GA}_{3}\right)(1 \mathrm{x}$ and $2 \mathrm{x})$, and aminoethoxyvinylglycine (AVG)] on immature 'Western' pecan nonfruiting shoots in 2016. No fruiting shoots were studied on these trees. Least squares means (lsmeans) are reported of each subsequent season return bloom parameter. Upper case A or B within column (return bloom and fruiting status) indicates that estimates sharing the same letter do not differ significantly $(P \leq 0.05)$.

\begin{tabular}{|c|c|c|c|c|c|}
\hline & Flowers per new shoot & $\begin{array}{l}\text { Flowers per previous } \\
\text { season shoot }\end{array}$ & New shoots & Flowers per cluster & $\begin{array}{l}\text { Percentage of new } \\
\text { shoots with flowers }\end{array}$ \\
\hline Control & $2.56 \mathrm{~A}$ & 6.28 & 2.48 & 3.99 & $63.3 \mathrm{~A}$ \\
\hline $\mathrm{GA}_{3}(2 \mathrm{x})$ & $0.30 \mathrm{~B}$ & 0.80 & 1.86 & - & $3.13 \mathrm{~B}$ \\
\hline AVG & $1.86 \mathrm{~A}$ & 6.11 & 3.31 & 3.50 & $48.4 \mathrm{~A}$ \\
\hline \multicolumn{6}{|l|}{ Source } \\
\hline
\end{tabular}


the following season. That is, fruiting shoots were noticeably longer and had higher numbers of leaves and buds, as well as larger individual leaf sizes (M.Y. Thompson, personal observations).

This study was performed only on protandrous-type pecan cultivars, and further work is needed for protogynous types. Furthermore, other than a study on the use of AVG (Wood et al., 2009), the use of PGRs to control $\mathrm{AB}$ in pecans growing in the Southwest United States had not been explored previously. With further study, PGRs, such as $\mathrm{GA}_{3}$, could be a powerful tool for growers to control shoot development and fruit production, as is already done in some other fruit crops.

\section{Literature Cited}

Bukovac, M.J., P. Sabbatini, and P.G. Schwallier. 2006. Modifying alternate bearing of spur-type 'Delicious' apple with ethephon. HortScience 41:1606-1611.

Chang, C.W. 1953. Chemical properties of alkali soils in Mesilla Valley, New Mexico. Soil Science 75:233-242.

Community Collaborative Rain, Hail \& Snow Network. 2018. List days with hail reports. 19 Nov. 2018. <https://www.cocorahs.org/ViewData/ListDaysWithHail.aspx $>$.

Ebert, A. and F. Bangerth. 1981. Relations between the concentration of diffusible and extractable gibberellins-like substances and the alternate bearing behavior in apple as affected by chemical fruit thinning. Scientia Hort. 15:45-52.

Greene, D.W. 2000. Reducing floral initiation and return bloom in pome fruit trees - applications and implications. HortTechnology 10:740743.

Hagemann, M.H., R. Winterhagen, M. Hegele, and J.N. Wünsche. 2015. Ethephon induced abscission in mango: Physiological fruitlet responses. Front. Plant Sci. 6:706.

Hassankhah, A., M. Rahemi, M.R. Mozafari, and K. Vahdati. 2018. Flower development in walnut: Altering the flowering pattern by gibberellic acid application. Notulae Botanicae Horti Agrobotanici Cluj-Napoca 46:700-706.

Jaillais, Y. and J. Chory. 2010. Unraveling the paradoxes of plant hormone signaling integration. Nat. Struct. Mol. Biol. 17:642-645.

Malm, N.R. 2003. Climate guide Las Cruces, 1892-2000. NMSU Cooperative Extension Service. Guide 749. 28 May 2017. <http:// aces.nmsu.edu/pubs/research/weather_climate/ RR749.pdf $>$.

Moyers, B.T. 2018. Symphony of the Regulators: How do plants control complex responses to environmental signals? Plant Cell 30:258-259.

Muñoz-Fambuena, N., C. Mesejo, M.C. Gonzalez-Mas, E. Primo-Millo, M. Agusti, and D. Iglesias. 2012. Fruit load modulates flowering-related gene expression in buds of alternate-bearing 'Moncada' mandarin. Ann. Bot. 110:1109-1118.

New Mexico Climate Center. 2016. Weather Station Data: New Mexico State Climate Center. New Mexico State University, Las Cruces, NM. 16 Aug. 2016. <https://weather.nmsu.edu/>.
Ramsey, F.L. and D.W. Schafer. 2002. The statistical sleuth. Duxbury, Australia.

Schmidt, T., D.C. Elfving, J.R. McFerson, and M.D. Whiting. 2009. Crop load overwhelms effects of gibberellic acid and ethephon on floral initiation in apple. HortScience 44: 1900-1906.

Sedgley, M. 1990. Flowering of deciduous perennial fruit crops. Hort. Rev. 12:223-264.

Soil Survey Staff, Natural Resources Conservation Service, US Department of Agriculture. Web Soil Survey. 2 Mar. 2017. <https://websoilsurvey. sc.egov.usda.gov/>.

Tromp, J. 1982. Flower-bud formation in apple as affected by various gibberellins. J. Hort. Sci. 57:277-282.

Wood, B.W. 1983. Changes in indoleacetic-acid, abscisic-acid, gibberellins, and cytokinins during budbreak in pecan. J. Amer. Soc. Hort. Sci. 108:333-338.

Wood, B.W. 2003. Pecan production in North America. Southwestern Entomologist Suppl. 27:1-19.

Wood, B.W. 2011a. Influence of aminoethoxyvinylglycine (AVG) on yield and quality of nut crops from a commercial pecan orchard. HortScience 46:586-589.

Wood, B.W. 2011b. Influence of plant bioregulators on pecan flowering and implications for regulation of pistillate flower initiation. HortScience 46:870-877.

Wood, B.W., L. Lombardini, and R.J. Heerema. 2009. Influence of aminoethoxyvinylglycine on pecan fruit retention. HortScience 44:1884 1889 . 